\title{
Analisis Penentuan Komposisi Optimum Kargo Dan Pax Pesawat Boeing 787 - 8 Dan Airbus 330 - 900 Pada Rute Jakarta - Dubai Menggunakan Optimasi Linear Programming
}

\author{
Fernando F Rotty ${ }^{[1] *}$., Freddy Franciscus ${ }^{[2]}$, Ericko Chandra ${ }^{[2]}$ \\ Prodi Teknik Penerbangan, Fakultas Teknologi Kedirgantaraan, Universitas Dirgantara \\ Marsekal Suryadarma, Jl. Halim Perdanakusuma, RT.1/RW.9, Halim Perdana Kusuma, \\ Kec. Makasar, Kota Jakarta Timur, Daerah Khusus Ibukota Jakarta 13610, Indonesia. \\ *Corresponding Author: fernandorotty11@gmail.com
}

\begin{abstract}
The need for airplanes is increasing every day, this is due to the increasing number of passengers and cargo shipments from one area to another. Therefore, airlines need to provide optimal, safe, and efficient cargo and passenger transportation services so that the delivery of goods and passengers can run according to correct procedures. Opportunities in the business of transporting passengers and shipping cargo must be utilized properly by each airline by purchasing planes so that the shipping process from one area to another can quickly arrive at its destination. The purpose of this paper is to find the optimum value of the two aircraft between the Boeing 787-8 and the Airbus 330900 in terms of the effect on the range, operational costs and to find out which aircraft is more profitable for operating costs on the Jakarta - Dubai route, using linear optimization. programming. Based on the results of the analysis that the optimum point for the calculation of linear programming optimization, the Boeing 787-8 aircraft obtained results (Max payload 41,075 kg, Fuel 6,657 kg, Max Fuel 101,323 kg) where these three results become a limitation for airlines to know the maximum usage of payload and fuel compared Airbus 330-900 aircraft obtained results at the point (Max payload 45,000 kg, Fuel 4,728 $\mathrm{kg}$, Max Fuel 111,272 kg) so that the optimization results are obtained, for Boeing 787-8 aircraft with a max payload of 41,075 kg, max pax 359, max cargo 15,945 $\mathrm{kg}$, compared to Airbus 330-900 with a max payload of 45,000 kg, max pax 460, max cargo 12,800 kg, so it can be concluded that the results of linear programming optimization and the calculation of the operational costs of the Boeing 787-8 aircraft are more optimal with a figure of Rp. 1,541,334,803.96 but in terms of revenue the Airbus 330-900 is bigger than the Boeing 787-8.
\end{abstract}

Keywords : Boeing 787-8, Airbus 330-900, Optimization Linear Programming, Optimization cargo and pax, Jakarta-Dubai. 


\section{Pendahuluan}

Penerbangan merupakan salah satu angkutan transportasi yang memiliki peran besar dalam dunia kedirgantaraan untuk mempercepat waktu dari satu daerah ke daerah lainnya. Hal tersebut dikarenakan semakin meningkatnya jumlah penumpang dan pengiriman kargo. Oleh karena itu penerbangan perlu menyediakan jasa angkutan kargo dan penumpang yang optimal, aman, dan efisien agar pengiriman barang dan penumpang dapat berjalan sesuai dengan prosedur yang benar.

Menurut IATA (2005) Kargo adalah semua barang yang diangkut atau yang akan diangkut dengan pesawat udara dengan menggunakan Air Way Bill / SMU (surat muatan udara) tetapi tidak termasuk pos atau barang lain yang dimuat dalam perjanjian konvensi pos internasional dan bagasi yang disertai tiket penumpang atau check baggage. ${ }^{[1]}$ Prospek angkutan kargo juga dipengaruhi oleh jenis pesawat apa yang digunakan.

Pada saat ini kegiatan penerbangan kargo dan passenger mengalami banyak persaingan antara maskapai penumpang dengan kargo, contohnya seperti Lion, Garuda, Sriwijaya yang saat ini berkembang untuk meningkatkan peluang bisnis di dunia kargo dan juga angkutan penumpang, maka dari itu maskapai banyak yang menggabungkan antara pesawat penumpang dengan kargo agar mendapatkan pendapatan yang maksimal serta mengefisiensi keadaan di lapangan.

Kegiatan kargo saat ini banyak dilakukan oleh maskapai dengan tujuan ke luar negeri dibandingkan dalam negeri dikarenakan memilik value yang besar seperti, pembayaran kurs mata uang negara asing, memperkenalkan produk dalam negeri sehingga sangat menguntungkan bagi pihak maskapai maupun angkutan kargo dalam negeri. Maka dari itu penulis memilih rute Jakarta-Dubai dikarenakan Dubai merupakan salah satu pusat wisata, bisnis dan perdagangan di dunia dan biasanya bahan ekspor yang dikirim melalui udara yaitu bahan non migas (timah, batubara, nikel, intan, tembaga), Rempah-rempah, Alat kecantikan, obatobatan, bahan makanan, makanan (ikan), hewan hidup, peti jenazah. ${ }^{[2]}$

Untuk mempermudah analisis penulis menggunakan metode linear programming yaitu metode matematik dalam mengalokasikan sumber daya yang langka untuk mencapai tujuan tunggal seperti memaksimumkan keuntungan atau meminimumkan biaya maskapai. Berdasarkan latar belakang di atas, maka penelitian ini dilakukan analisis penentuan komposisi optimum kargo dan pax pesawat Boeing 787-8 dan Airbus 330-900 pada rute JakartaDubai menggunakan optimasi linear programming.

\section{Metode Penelitian}

\subsection{Prosedur Penelitian}

Berdasarkan Flowchart yang sudah dibuat bahwa Penelitian ini menggunakan metode optimasi linear programming, Awalnya dengan Memasukan jenis pesawat yang akan dianalisa untuk memecahkan suatu masalah dalam penelitian yang akan diolah, lalu Memproses perbandingan data Spesifikasi kedua pesawat, Apakah data spesifikasi kedua pesawat sudah sesuai dengan pembahasan ? jika tidak maka tidak perlu dilanjutkan, karena spesifikasi nya tidak sesuai, Jika iya maka dapat dilanjutkan dengan proses komposisi kargo dan pax terhadap kedua pesawat, selanjutnya Melakukan proses Komposisi kargo dan pax terhadap 
kedua pesawatdari proses itu maka dapat Melakukan perhitungan linear programming payload dan fuel, payload dan range, Dari perhitungan linear programming payload dan fuel, apakah mendapatkan titik optimum dari hasil grafik? Jika tidak maka melakukan perhitungan ulang linear programming antara payload dan fuel. Jika iya maka di lanjutkan dengan perhitungan optimasi linear programming pax dan kargo, dengan Melakukan perhitungan optimasi linear programming pax dan kargo, Dari perhitungan tersebut apakah hasil optimasi Linear programming sudah sesuai dengan komposisi kargo dan pax? Jika tidak maka check kembali komposisi pada kargo dan pax kedua pesawat, jika iya maka dilanjutkan maka dilanjutkan dengan operasional Melakukan perhitungan kedua perhitungan biaya pesawat, biaya operasional kedua pesawat, Apakah profit atau pendapatan yang didapatkan sudah sesuai ? jika tidak maka hitung kembali optimasi linear programming max pax dan max kargo, jika iya dilanjutkan dengan tingkat kekerasan runway. Selanjutnya Melakukan proses penambahan teori dalam skripsi ini mengenai tingkat kekerasan runway, Dari semua proses kita Mendapatkan hasil dan analisis kesimpulan dari tujuan penelitian tersebut.

\subsection{Optimasi Linear Programming.}

Optimasi Linear Programmin bisa digunakan untuk melihat mana yang lebih menguntungkan dan mengharuskan penumpang membayar lebih untuk bagasi dengan resiko kehilangan calon penumpang, atau menggratiskan biaya bagasi dengan resiko biaya fuel lebih tinggi. Untuk mempermudah, maskapai melakukan optimasi sebagai berikut Konsumsi fuel minimum, berat pesawat diminimumkan.
Semakin berat kargo, konsumsi fuel semakin besar. Jika pendapatan dari pengangkutan kargo relatif kecil dibandingkan penambahan biaya fuel, maka lebih baik tidak membawa kargo atau tarif kargo dinaikkan, maka dari itu metode optimasi linear berperan untuk mendapatkan nilai terbaik terhadap spesifikasi data dari kedua pesawat seperti MTOW (Maximum Take Off Weight), OEW (Optimum Empty Weight), Maksimum Payload dan juga Maksimum Fuel.

\subsection{Spesifikasi Pesawat.}

Pada sub bab ini akan menjelaskan mengenai spesifikasi kedua pesawat.

Tabel 2.1 Spesifikasi Pesawat Boeing 787-8.

\begin{tabular}{|c|l|}
\hline Spesifikasi & \\
\hline & $\frac{\text { Rolls- }}{\text { Royce }}$ \\
\hline Engine & $\frac{1}{\frac{\text { Trent }}{1000}}$ \\
\hline Maksimum payload & 41.075 \\
$\mathrm{~kg}$ \\
\hline Maksimum Fuel & 126.206 \\
\hline Asumsi Berat Badan & $\mathrm{L}$ \\
\hline Max Pax & 359 \\
\hline MTOW & 227.930 \\
\hline OEW & $\mathrm{kg}$ \\
\hline Kargo Demand & $\mathrm{kg}$ \\
\hline & $4,826 \mathrm{ft}^{3}$ \\
\hline & \multicolumn{2}{|l}{} \\
\hline
\end{tabular}


Tabel 2.4 Spesifikasi Pesawat Airbus $330-900 .{ }^{[8]}$

\begin{tabular}{|c|c|}
\hline Spesifikasi & \\
\hline Engine & $\begin{array}{l}\frac{\text { Rolls- }}{\text { Royce }} \\
\frac{\text { Trent }}{7000-72} \\
\end{array}$ \\
\hline Maksimum payload & $\begin{array}{l}45.000 \\
\mathrm{~kg}\end{array}$ \\
\hline Maksimum Fuel & $L^{139.090}$ \\
\hline Asumsi Berat Badan & $70 \mathrm{Kg}$ \\
\hline Max Pax & 460 \\
\hline MTOW & $\begin{array}{l}251.000 \\
\mathrm{~kg}\end{array}$ \\
\hline OEW & \begin{tabular}{|l|}
135.000 \\
$\mathrm{~kg}$
\end{tabular} \\
\hline Kargo Demand & $\begin{array}{l}33 \text { LD3 } \\
\text { or } 9 \\
\text { pallets + } \\
5 \text { LD3 }\end{array}$ \\
\hline
\end{tabular}

\section{Hasil dan Pembahasan}

\subsection{Perbandingan Data Spesifikasi \\ Kedua Pesawat}

Sebelum menganalisis komposisi kargo dan pax dibutuhkan perbandingan data spesifikasi kedua pesawat untuk mengetahui nilai persamaan matematika batasan dari kapasitas kursi (pax) dan maksimum payload.

Penjelasan dari kedua spesifikasi pesawat, bahwa pesawat Boeing 787-8 memiliki muatan payload dan pax lebih sedikit dibandingkan pesawat Airbus 330-900. Dengan total jumlah, maksimum payload $41.075 \mathrm{~kg}$, maksimum pax 359 untuk Boeing 787-8, dan maksimum payload $45.000 \mathrm{~kg}$, maksimum pax 460 untuk Airbus 330900. Data tersebut diambil dari spesifikasi pabrik pesawat Boeing dan Airbus, dan digunakan untuk perhitungan optimasi linear programming serta perhitungan biaya operasional.

\subsection{Komposisi Kargo dan Pax}

Untuk memvariasikan jumlah pax dan jumlah kargo yang didapat, maka dari itu diperlukan revenue dan persamaan matematika untuk membatasi kapasitas kursi dan maksimum payload dari data spesifikasi berat pesawat terbang. Berikut komposisi terhadap kedua pesawat :

Boeing 787-8

Constrain 1 Kapasitas pesawat

P. $70+$ Xc $<=$ Max Payload

P. $70+X c<=41.075$

Constrain 2 Jumlah penumpang dibatasi jumlah kursi tersedia $\mathrm{Xt}<=$ Jumlah kursi

$\mathrm{Xt}<=359$

Constrain 3 Jumlah kargo dibatasi oleh permintaan (demand) kargo

$X_{\mathrm{c}}<=\mathrm{dk}$

$X_{c}<=15.000 \mathrm{~kg}$

Constrain 4 Jumlah kargo dibatasi oleh kapasitas ruang kargo volume

$\mathrm{Xc}_{\mathrm{c}}<=\mathrm{ck}$

$\mathrm{Xc}_{\mathrm{c}}<=4,826 \mathrm{ft}^{3} / 136.7 \mathrm{~m}^{3}$

28 ((LD3_ (Load Device kubik) or 9 $88 \times 125$ pallets))

Airbus 330-900

Constrain 1 Kapasitas pesawat :

P. $70+$ Xc $<=$ Max Payload

P. $70+\mathrm{Xc}<=45.000$

Constrain 2 Jumlah penumpang dibatasi jumlah kursi tersedia

$\mathrm{Xt}<=$ Jumlah kursi $\mathrm{Xt}<=460$

Constrain 3 Jumlah kargo dibatasi oleh Permintaan (demand) kargo

$X \mathrm{c}<=\mathrm{dk}$

$X_{c}<=15.000 \mathrm{~kg}$

Constrain 4 Jumlah kargo dibatasi oleh kapasitas ruang kargo volume

$\mathrm{Xc}<=\mathrm{ck}$

$X_{c}<=33$ LD3 (Load device kubik) or 9 pallets +5 LD3

Dari persamaan keseluruhan diatas, bahwa persamaan tersebut digunakan 
Jurnal Teknologi Kedirgantaraan, Vol, VI No. 2, Agustus 2021, P-ISSN 2528-2778, E-ISSN 2684-9704 https://doi.org/10.35894/jtk.v6i2

untuk perhitungan Optimasi linear programming.

\subsection{Perhitungan Linear Programming Payload dan Fuel .}

Sebelum melakukan perhitungan optimasi pax dan kargo dibutuhkan perhitungan linear programming payload dan fuel untuk mendapatkan titik optimum. Berikut Perhitungan linear programming payload dan fuel dari kedua pesawat:

Tabel 3.1 Data Spesifikasi Berat Boeing 787-8 ${ }^{[8]}$

\begin{tabular}{|l|l|l|}
\hline $\begin{array}{c}\text { Spesifikasi } \\
\text { Berat }\end{array}$ & Hasil & Satuan \\
\hline OEW & 119.950 & $\mathrm{~kg}$ \\
\hline MTOW & 227.930 & $\mathrm{~kg}$ \\
\hline $\begin{array}{l}\text { MAX } \\
\text { PAYLOAD }\end{array}$ & 41.075 & $\mathrm{~kg}$ \\
\hline MAX FUEL & 101.323 & $\mathrm{~kg}$ \\
\hline
\end{tabular}

Berdasarkan data spesifikasi pesawat, di ketahui :

MTOW $=$ OEW + FUEL + PAYLOAD sehingga dapat dihitung :

Berat Payload + Fuel $=$ MTOW - OEW $=227.930 \mathrm{~kg}-119.950 \mathrm{~kg}$ $=107.980 \mathrm{~kg}$

Fuel $=107.980 \mathrm{~kg}-$ MAX PAYLOAD

$=107.980 \mathrm{~kg}-41.075 \mathrm{~kg}$ $=66.905 \mathrm{~kg}$

Payload $=107.980 \mathrm{~kg}-$ MAX FUEL $=107.980 \mathrm{~kg}-101.323 \mathrm{~kg}$ $=6.657 \mathrm{~kg}$
Tabel 3.2 Data Linear Programming Boeing 787-8

\begin{tabular}{|l|c|c|}
\hline Kondisi & Fuel & Payload \\
\hline $\begin{array}{l}\text { Payload } \\
\text { maksimum }\end{array}$ & 66.905 & 41.075 \\
\hline Fuel maksimum & 101.323 & 6.657 \\
\hline Payload = 0 & 107.980 & 0 \\
\hline
\end{tabular}

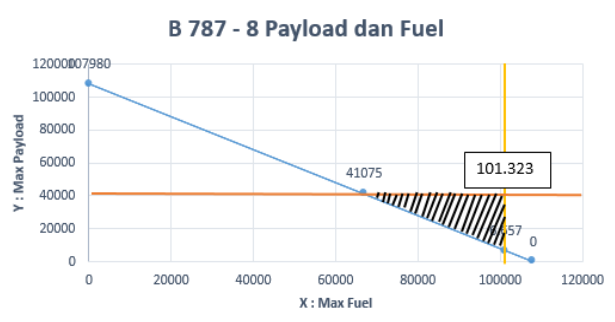

Gambar 3.1 Grafik Linear Programming Boeing 787-8

Kesimpulan dari grafik diatas adalah bahwa titik optimum dari pesawat Boeing $787-8$ ada pada titik $(41.075 \mathrm{~kg}, 6.657 \mathrm{~kg}$, $101.323 \mathrm{~kg}$ ). Ketiga titik tersebut menjadi batasan, dimana airlines dapat mengetahui pemakaian maksimum dari payload dan fuel. Titik saat maksimum payload digunakan maskapai untuk menentukan jarak terjauh dari rute yang bisa dibuka dengan memaksimalkan Pendapatan dari Payload, sedangkan titik saat maksimum fuel di gunakan maskapai jika ada rute terjauh dan payload yang bisa dibawa tidak maksimum.

\section{Airbus 330-900}

Grafik yang akan dibuat merupakan grafik yang menjadikan acuan untuk airlines berdasarkan data spesifikasi berat pesawat. Berikut data spesifikasi Airbus 330-900 : 
Tabel 3.3 Data Spesifikasi Berat Airbus 330-900[12]

\begin{tabular}{|l|l|l|}
\hline $\begin{array}{c}\text { Spesifikasi } \\
\text { Berat }\end{array}$ & Hasil & Satuan \\
\hline OEW & 135.000 & $\mathrm{~kg}$ \\
\hline MTOW & 251.000 & $\mathrm{~kg}$ \\
\hline $\begin{array}{l}\text { MAX } \\
\text { PAYLOAD }\end{array}$ & 45.000 & $\mathrm{~kg}$ \\
\hline MAX FUEL & 111.272 & $\mathrm{~kg}$ \\
\hline
\end{tabular}

Berdasarkan data spesifikasi pesawat, Di ketahui :

MTOW = OEW + FUEL + PAYLOAD sehingga dapat dihitung :

Berat Payload + Fuel $=$ MTOW - OEW

$=251.000 \mathrm{~kg}-135.000 \mathrm{~kg}$

$=116.000 \mathrm{~kg}$

Fuel $=116.000 \mathrm{~kg}-$ MAX PAYLOAD

$=116.000 \mathrm{~kg}-45.000 \mathrm{~kg}$

$=71.000 \mathrm{~kg}$

Payload $=116.000 \mathrm{~kg}-$ MAX FUEL

$=116.000 \mathrm{~kg}-111.272 \mathrm{~kg}$

$=4.728 \mathrm{~kg}$

Tabel 3.4 Data Linear Programming Airbus $330-900$

\begin{tabular}{|l|l|l|}
\hline Kondisi & $\mathrm{x}$ & $\mathrm{y}$ \\
\hline Payload maksimum & 71.000 & 45.000 \\
\hline Fuel maksimum & 111.272 & 4.728 \\
\hline Payload = 0 & 116.000 & 0 \\
\hline
\end{tabular}

A330 - 900 Neo Payload dan Fuel

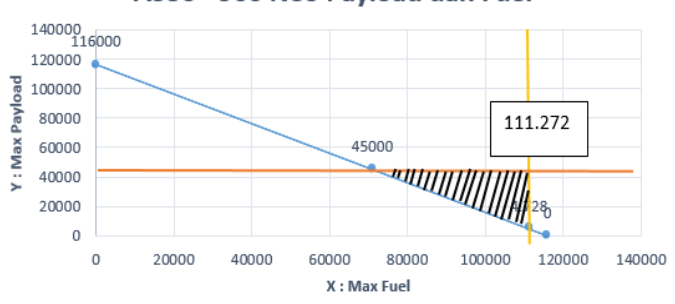

Gambar 3.2 Grafik Linear

ProgrammingAirbus 330-900.

Kesimpulan dari grafik diatas adalah bahwa titik optimum dari pesawat Airbus 330 - 900 ada pada titik $(45.000 \mathrm{~kg}, 4.728$ $\mathrm{kg}, 111.272 \mathrm{~kg}$ ) ketiga titik tersebut menjadi batasan, dimana airlines dapat mengetahui pemakaian maksimum dari payload dan fuel. Titik saat maksimum payload digunakan maskapai untuk menentukan jarak terjauh dari rute yang bisa dibuka dengan memaksimalkan pendapatan dari payload, Sedangkan titik saat maksimum fuel digunakan maskapai jika ada rute terjauh yang memerlukan fuel maksimum dan payload yang bisa dibawa tidak maksimum.

\subsubsection{Perhitungan Linear Programming Range dan Payload.}

Pada perhitungan ini maskapai dapat mengetahui Berapa max payload yang dapat di bawa dengan rute Jakarta Dubai yang memiliki total jarak $6544 \mathrm{~km}$ / $3533 \mathrm{~nm}$. Berikut perbandingan antaraRange/ Payload.

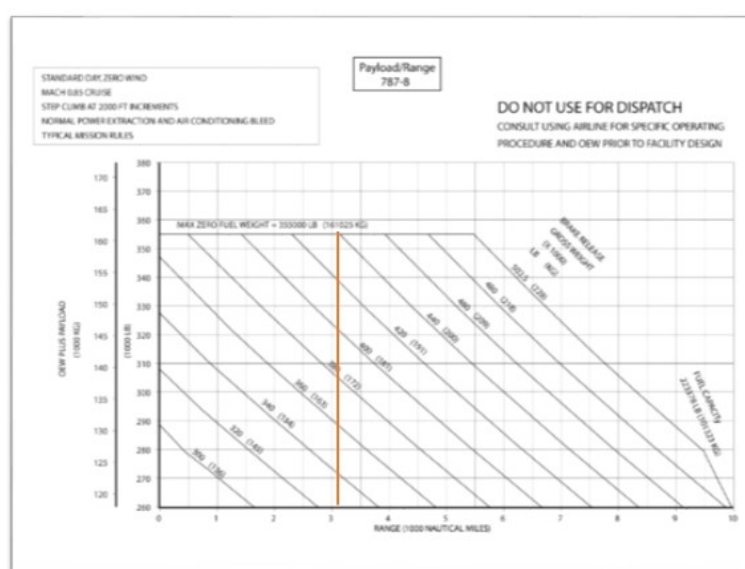

Gambar 3.3 Grafik Linear Payload

Range BOEING 787-8 (dengan penambahan garis) ${ }^{[8]}$

Tabel 3.5 Hasil Grafik Payload dan OEW

\begin{tabular}{|c|c|c|}
\hline $\begin{array}{c}\text { Max Zero } \\
\text { Fuel Weight }\end{array}$ & 161.025 & $\mathrm{~kg}$ \\
\hline OEW & 119.950 & $\mathrm{~kg}$ \\
\hline
\end{tabular}

Maksimum Zero Fuel Weight

$=$ OEW + Payload

$=119.950 \mathrm{~kg}+41.075 \mathrm{~kg}$

$=161.025 \mathrm{~kg}$ 
Jurnal Teknologi Kedirgantaraan, Vol, VI No. 2, Agustus 2021, P-ISSN 2528-2778, E-ISSN 2684-9704 https://doi.org/10.35894/jtk.v6i2

\author{
Max Payload \\ = Max Zero Fuel Weight - OEW Max \\ Payload \\ $=161.025 \mathrm{~kg}-119.950 \mathrm{~kg}$ \\ Max Payload \\ $=41.075 \mathrm{~kg}$
}

Dari hasil grafik di atas bahwa Payload yang dapat dibawa pada rute Jakarta Dubai ialah maksimum $41.075 \mathrm{~kg}$.

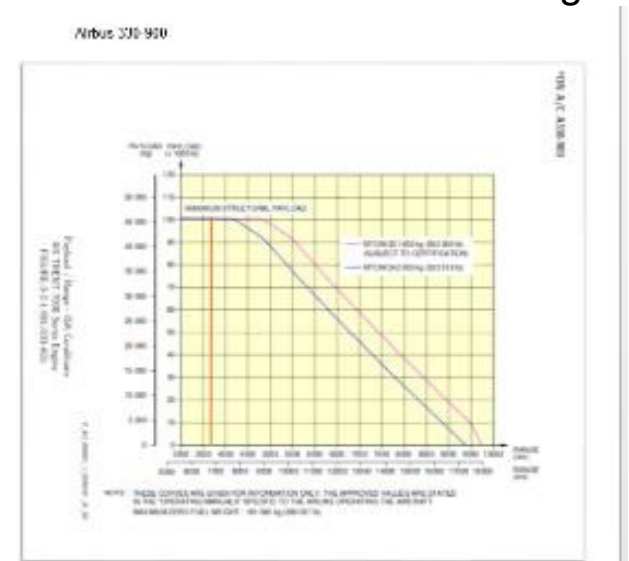

Gambar 3.4 Grafik Linear Payload Range AIRBUS 330-900 (dengan penambahan garis $)^{[9]}$

Dari hasil grafik di atas bahwa Payload yang dapat dibawa pada rute Jakarta Dubai ialah maksimum $45.000 \mathrm{~kg}$.

\subsection{Optimasi Linear Programming pax dan kargo}

Setalah mendapatkan titik optimum payload dan fuel, berikutnya dipergunakan optimasi linear programming pax dan kargo untuk menjadikan acuan terhadap airlines untuk mengetahui batasan kargo dan pax dari kedua pesawat. Berikut perhitungan optimasi linear programming.

\section{Boeing 787-8}

Untuk membuat grafik Optimasi linear programming pax dan kargo dibutuhkan studi kasus data payload kargo dan penumpang:

$$
\begin{array}{ll}
\text { Max payload } & =\text { Pax } .70+\text { kargo } \\
41.075 \mathrm{~kg} & =359 \times 70+\text { kargo }
\end{array}
$$

$$
\begin{array}{ll}
41.075 \mathrm{~kg} & =25.130 \mathrm{~kg}+\text { kargo } \\
\text { Kargo } & =41.075 \mathrm{~kg}-25.130 \mathrm{~kg} \\
\text { Kargo } & =15.945 \mathrm{~kg}
\end{array}
$$

Dari hasil kargo 15.945 kg, Maskapai dapat mengoperasikan dengan payload dan kursi penumpang tertentu dengan batasan jumlah $41.075 \mathrm{~kg}$. Hasil tersebut dibuat persamaan linear antara max pax dengan jumlah max kargo yang dapat dipakai.

Tabel 4.6 Data Pax dan Kargo Boeing 787-8

\begin{tabular}{|c|c|c|}
\hline \multicolumn{1}{|c|}{ Kondisi } & Passenger & Kargo \\
\hline $\begin{array}{l}\text { Passenger } \\
\text { Maksimum }\end{array}$ & 359 & 15.945 \\
\hline $\begin{array}{l}\text { Passenger } \\
=0\end{array}$ & 0 & 41.075 \\
\hline
\end{tabular}

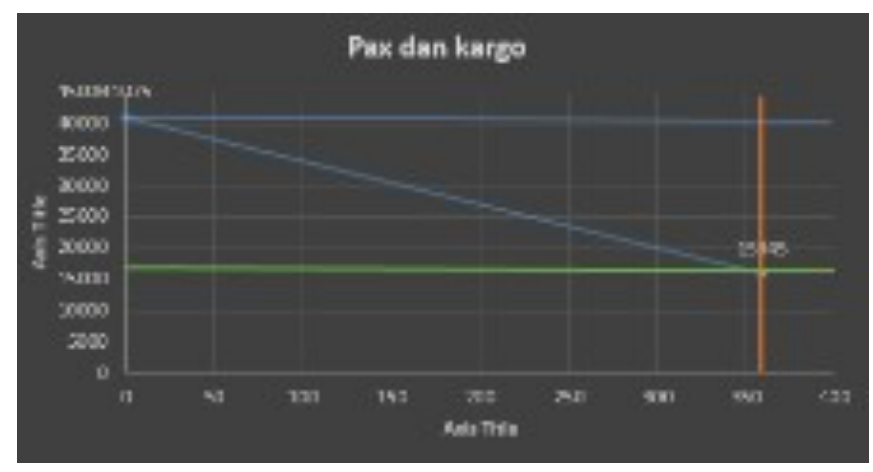

Gambar 3.5 Grafik Optimasi Linear Programming Boeing 787-8

Dari hasil Grafik diatas terlihat bahwa pesawat Boeing 787-8 dapat mengoperasikan rute Jakarta - Dubai dengan max payload $41.075 \mathrm{~kg}$ di bawah garis horizontal berwarna biru (sebagai batasan), dan max kargo $15.945 \mathrm{~kg}$ di atas garis horizontal berwarna hijau (sebagai batasan), serta max pax 359 (sebagai batasan) .

Airbus 330-900

Untuk membuat grafik Optimasi linear programming pax dan kargo dibutuhkan 
studi kasus data payload kargo dan penumpang :

$$
\begin{array}{ll}
\text { Max payload } & =\text { Pax .70 + kargo } \\
45.000 \mathrm{~kg} & =460 \times 70+\text { kargo } \\
45.000 \mathrm{~kg} & =32.200 \mathrm{~kg}+\text { kargo } \\
\text { kargo } & =12.800 \mathrm{~kg}
\end{array}
$$

Dari hasil kargo $12.800 \mathrm{~kg}$, Maskapai dapat mengoperasikan dengan payload dan kursi penumpang tertentu dengan batasan jumlah $45.000 \mathrm{~kg}$. Hasil tersebut dibuat persamaan linear antara max pax dengan jumlah max kargo yang dapat dipakai.

Tabel 4.7 Data Pax dan Kargo Airbus 330-900

\begin{tabular}{|c|l|c|}
\hline \multicolumn{1}{|c|}{ Kondisi } & Passenger & Kargo \\
\hline $\begin{array}{l}\text { Passenger } \\
\text { Maksimum }\end{array}$ & 460 & 12.800 \\
\hline $\begin{array}{l}\text { Passenger } \\
=0\end{array}$ & 0 & 45.000 \\
\hline
\end{tabular}

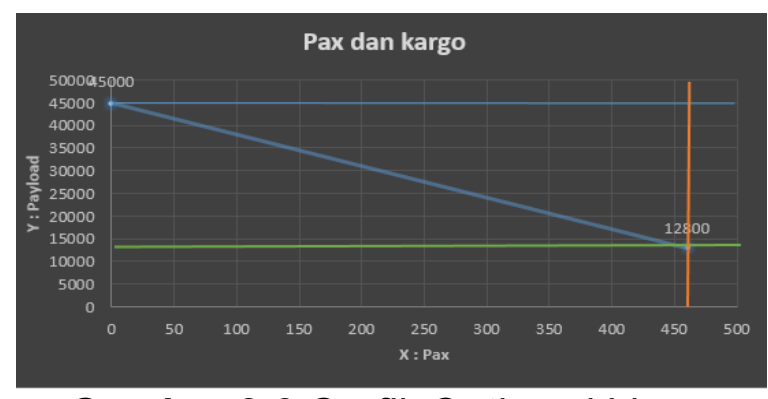

Gambar 3.6 Grafik Optimasi Linear Programming Airbus 330-900

Dari hasil Grafik diatas terlihat bahwa pesawat Airbus 330-900 dapat mengoperasikan rute Jakarta - Dubai dengan max payload $45.000 \mathrm{~kg}$ di bawah garis horizontal berwarna biru (sebagai batasan), dan max kargo $12.800 \mathrm{~kg}$ di atas garis horizontal berwarna hijau (sebagai batasan), serta max pax 460 (sebagai batasan).

Dari grafik Optimasi Linear programming kedua pesawat, dimana hasil batasan seperti Max kargo, Max Payload, dan Max Pax dijadikan sebagai perhitungan biaya operasional dari kedua pesawat agar mendapatkan hasil yang optimum dalam cost penerbangan Jakarta - Dubai.

\subsection{Perhitungan Biaya Operasional}

Setelah didapatkan perhitungan optimasi linear programming seperti max payload, max kargo dan max pax guna untuk mencari profit dan perhitungan biaya operasional yang paling optimum.

\begin{tabular}{|l|l|l|}
\hline COST & \multicolumn{1}{|c|}{$\begin{array}{c}\text { BOEING } \\
787-8\end{array}$} & \multicolumn{1}{|c|}{$\begin{array}{l}\text { AIRBUS } \\
330-900\end{array}$} \\
\hline ASK & 2.349 .296 & 3.010 .240 \\
\hline RPK & 1.174 .648 & 1.505 .120 \\
\hline LF & $50 \%$ & $50 \%$ \\
\hline FUEL & 943.360 .50 & 1.001 .100 .0 \\
\hline $\begin{array}{l}\text { LANDING } \\
\text { FEE }\end{array}$ & $4.752 .457,6$ & $4.752 .457,6$ \\
\hline MAINTENA & 244.750 .37 & 285.626 .96 \\
NCE & 1,6 & 5,1 \\
\hline CREW & 344.947 .53 & 380.675 .65 \\
COST & 0,2 & 3,1 \\
\hline $\begin{array}{l}\text { TOTAL } \\
\text { BIAYA } \\
\text { OPERASIO }\end{array}$ & 1.541 .334 .8 & 1.676 .670 .4 \\
NAL & 03,96 & 36,36 \\
\hline
\end{tabular}

Total Biaya diatas merupakan total biaya per pax dan per kargo yang dibutuhkan oleh maskapai untuk mengoperasikan satu pesawat.

Dari hasil tabel diatas terlihat bahwa pesawat Boeing 787-8 biaya operasional atau pengeluarannya lebih sedikit dengan angka $\mathrm{Rp}$ 1.541.334.803,96 dibandingkan Airbus 330-900 dengan angka $\mathrm{Rp} 1.676 .670 .436,36$. Hal ini 
Jurnal Teknologi Kedirgantaraan, Vol, VI No. 2, Agustus 2021, P-ISSN 2528-2778, E-ISSN 2684-9704 https://doi.org/10.35894/jtk.v6i2

disebabkan karena cost yang lebih rendah dan Capacity dari payload, pax, dan fuel yang berpengaruh terhadap biaya operasional.

\subsection{Tingkat Kekerasan Runway Dari Kedua Bandara. \\ Kekerasan Runway tergantung dari spesifikasi ACN dan PCN. Panjang Runway terkait dengan performa pesawat yaitu kemampuan kecepatan lift tergantung dari panjang runway.}

\subsubsection{Perhitungan PCN dan ACN} Airbus330-900

Bandara Dubai Mempunyai Klasifikasi sebagai berikut :

PCN $140 \mathrm{~F} / \mathrm{A} / \mathrm{X} / \mathrm{T}$

(Fleksibel / High / Medium Limitation $1.75 \mathrm{Mpa} /$ Technical Evaluation) $\mathrm{ACN}=50,81$ (Dengan angka tersebut Pesawat Airbus 330-900 dapat mendarat pada Dubai International Airport).

Bandara CGK Mempunyai Klasifikasi sebagai berikut :

PCN $120 \mathrm{R} / \mathrm{D} / \mathrm{W} / \mathrm{T}$

(Rigid / Ultra Low / High No Limit / Technical Evaluation.) Mencari Nilai ACN dengan rumus [30] : $\mathrm{ACN}=69,79$ (Dengan angka tersebut Pesawat Airbus 330-900 dapat mendarat pada Bandara Soekarno Hatta)

Boeing 787-8

Bandara Dubai Mempunyai Klasifikasi sebagai berikut :

PCN $140 \mathrm{~F} / \mathrm{A} / \mathrm{X} / \mathrm{T}$

(Fleksibel / High / Medium Limitation 1.75 Mpa / Technical Evaluation.) $\mathrm{ACN}=55,86$ (Dengan angka tersebut Pesawat Boeing 787-8 dapat mendarat pada Dubai International Airport). Bandara CGK Mempunyai Klasifikasi sebagai berikut :
PCN $120 \mathrm{R} / \mathrm{D} / \mathrm{W} / \mathrm{T}$

(Rigid / Ultra Low / High No Limit / Technical Evaluation.)

$\mathrm{ACN}=80,66$ (Dengan angka tersebut Pesawat Boeing 787-8 dapat mendarat pada Bandara Soekarno Hatta)

\section{IV.KESIMPULAN}

Berdasarkan hasil analisis maka dapat diambil kesimpulan :

1. Pesawat Boeing 787-8 memiliki kapasitas payload $41.075 \mathrm{~kg}$, dengan jumlah kursi penumpang sejumlah 359 , serta kapasitas kargo sebesar 28 LD3 dan Pesawat Airbus 330-900 memiliki kapasitas payload adalah $45.000 \mathrm{~kg}$, dengan Jumlah kursi penumpang, sebanyak 460 , serta kapasitas kargo sebesar 33 LD3. Hal ini berarti pesawat Boeing 787-8 memiliki muatan yang lebih kecil dibandingkan pesawat Airbus 330900.

2. Titik yang berpotensi optimum payload dan fuel pesawat Boeing 7878 ada pada titik $41.075 \mathrm{~kg}, 6.657 \mathrm{~kg}$, dan $101.323 \mathrm{~kg}$ sedangkan Airbus pada titik $45.000 \mathrm{~kg}, 4.728 \mathrm{~kg}$, dan $111.272 \mathrm{~kg}$. Titik optimum komposisi pax dan kargo Boeing 787-8 ada pada titik 359, $15.945 \mathrm{~kg}$, dan Airbus 330900 ada pada titik 460, $12.800 \mathrm{~kg}$.

3. Nilai terbaik untuk biaya operasional ada pada pesawat Boeing 787-8, disertai bahwa Bandara Soekarno Hatta dengan Bandara Dubai dapat menerima beban dari kedua pesawat.

\section{V.DAFTAR PUSTAKA}

[1] Boeing Commercial Airplanes.,2018 , 787 Airplane Characteristics For Airport Planning Data, Doc number D6- 58333 : Rev $M$, Boeing.

[2] Airbus S.A.S., Rev No. 29, 2020, Aircraft Characteristics Airport And 
Jurnal Teknologi Kedirgantaraan, Vol, VI No. 2, Agustus 2021, P-ISSN 2528-2778, E-ISSN 2684-9704 https://doi.org/10.35894/jtk.v6i2

Maintenance Planning. AC 330 : Airbus

[3] Widiyahartanti. D, $\mathrm{Na}$ Sjafaat., 2007, Perencanaan Perpanjangan Landasan Pacu Bandar Udara Ahmad Yani Semarang : Volume2 eprints undip jurnal Fakultas teknik., Semarang (Halaman 1-3), (Halaman 16-18),

[4] ICAO, Amandment 15, Volume 1, 2020 : Annex 14 Aerodromes

[5] Airbus S.A.S., 2020 Edition, Family Figures: AC 330.

[6] Nugroho, F., 2013. Weight and BalanceBerat Pesawat ,http://www.ilmuterbang.com/artik el-mainmenu-29/teoripenerbangan-mainmenu-68/712weightabalance-berat-pesawat. Diaksespada tanggal 3 November 2020.

[7] Hiller F.S, Gerald J.Lieberman, K. Schmedders, M. Stephens, M. Hiller, and M.O Sullivan 2000., Introduction to Operations Research : 7th ed.

[8] Chaerani. D, Eman, E. Hartini, 2019, Buku ajar pemograman linear :Bitread Digital Publishing, Jakarta.

[9] ICAO, Secretariat, 2009, Tenth Session Of The Statistics Division, Available Capacity And Average Passenger Mass, STA/10WP/513/10/09, Montreal.

[10] Widiastuti. R, A. Setiawan, Y. Indrianingsih., 2012, Analisis Direct Operaring Cost Dalam Sistem Pendukung Keputusan Penentuan Tipe Pesawat Terbang Untuk Pembukaan Rute Baru Penerbangan, Volume 1 Jurnal, : STTA Jurusan Teknik Informatika, Yogyakarta.

[11] Nasution., H.M.N 1996. Manajemen Transportasi : Ghalia., Indonesia
[12] Garuda Indonesia, Bloomberg., 2018, Glossarium https://www.garudaindonesia.com/sa/en/investorrelations/companydata/glossarium/index. Diakses pada tanggal 15 November 2020.

[13] Dubai Airport (DXB) Information., 2009, Airportin Dubai Area, United Arab Emirates : http://www.dubaidxb.airports- quides.com/.

Diakses pada tanggal 15 November 2020.

[14] Fubra Limited., 2020, World Airport Codes, https://www.world- airportcodes.com/indonesia/soekarnohatta-international-11402.html. Diaksespada tanggal 3 November 2020.

[15] Fubra Limited., 2020, World Airport Codes, https://www.worldairport-codes.com/united-arabemirates/dubai-international2003.html. Diakses pada tanggal 3 November 2020.

[16] Jetphotos., 2020, Boeing 787 dreamliner.Jpg, https://www.jetphotos.com/photo/95 20695 Diakses pada tanggal 16 November 2020.

[17] Avia Tren., 2019, A330neo Pertama Garuda Indonesia.Jpg, http://aviatren.com/2019/03/05/a3 30neo-pertama-garuda- indonesiadikirim-september- 2019/. Diakses pada tanggal 16 November 2020.

[18] Dubai Airport, 2020, Dubai International Airport Charges (Commercial), https://www.dubaiairports.ae/doc s/defaultsource/Publications/dubai-intl(airport-charges)commercial.pdf?sfursn $=0$. Diakses pada tanggal 11 Januari 2021. 
Jurnal Teknologi Kedirgantaraan, Vol, VI No. 2, Agustus 2021, P-ISSN 2528-2778, E-ISSN 2684-9704

https://doi.org/10.35894/jtk.v6i2

[19] Bhaskara Vinay, 2014 : Analysis The 330-900 neo has a viable business case.Airways magazine, miami

[20] AIP UNITED ARAB EMIRATES, AD 2.OMDW-1, 2016 https://www.platinumairways.org/f iles/DOTW Charts/OMDWCharts 201605.pdf. Di akses pada tanggal 13 Januari 2021.

[21] Nugroho Fadjar, 2010, Pavement Classification Number / Aircraft Classification Number http://www.ilmuterbang.com/artik el-mainmenu 29/teoripenerbangan-mainmenu-68/301pavement-classification-numberaircraft-classification-number.

Di akses pada tanggal 13 januari 2021. 